\title{
PENSAR LA EDUCACIÓN PARA EL DESARROLLO FÍSICO Y DEPORTIVO EN PANDEMIA COVID-19
}

En estos tiempos cuando se está viviendo un estado de pandemia a nivel mundial por el virus SARS-CoV-2 causante de la enfermedad Covid19, son bien significativos los cambios que se han generado a todos los niveles y en todas las esferas de la actividad humana desde el inicio de su proliferación en diciembre de 2019. En tal sentido, independientemente de los estudios científicos y prácticas médicas adelantadas en estos dos años, la realidad ha hecho que el mundo asuma abruptamente nuevos escenarios. La emergencia de una nueva sociedad descrita como "la sociedad del metro y medio" (Medina, 2020), viene a estar determinada por normas de bioseguridad como el distanciamiento social. Situación que ya es parte de nuestra vida cotidiana y, al parecer, lo será por mucho tiempo, pues, los virus pandémicos son imprevisibles.

Considerando lo anterior, es menester que razonemos de Educación en «este tiempo», «estos días», "esta época» como un instante en el que los hechos, las cosas y las palabras se salieron de eje. Es un tiempo enrarecido. La pandemia nos envolvió sin aviso, lo que estamos pasando en esta emergencia puede expresarse como un infortunio generalizado. El coronavirus ha alcanzado y alcanzará efectos adversos en términos de salud física, en las áreas de salud mental, con consecuencias sociales, económicas educativas y culturales que son difíciles de calcular.

Es una de las peores noticias que le ha sucedido a la humanidad en estos tiempos del siglo XXI. Son considerables los daños y las pérdidas de vidas humanas son significativas, así como los efectos colaterales desde el punto de vista social y psicológico. ¿Qué respuesta tenemos para contener o contrarrestar estas elevadas afectaciones? En diversas áreas del saber y de la actividad humana es necesario seguir activando, multiplicando y creando nuevas estrategias de mitigación.

Si centramos nuestra atención en la salud física y mental, una de las áreas que más ha aportado beneficios durante varios períodos antes de la pandemia y durante la cuarentena, es la actividad física, el deporte y la recreación excelentes aliados para la salud. Resalta la UNESCO en su Proclama de Carta Internacional que sitúa la educación física, la actividad física y el deporte al servicio del desarrollo humano e insta a todos y en especial a los gobiernos, las organizaciones intergubernamentales, las organizaciones deportivas, a adherirse a esta Carta y difundirla a fin de que sus principios puedan convertirse en realidad para todos los seres humanos. 
Es necesario y urgente la promoción de estilos de vida vigorosa durante la pandemia asociada a Covid19, desde los espacios virtuales escolares programas dirigidos a optimizar el ambiente y la sociedad en que se habita, por otra parte, se debe perfeccionar las capacidades de las personas para llevar una vida más sana.

La pandemia ha obligado a la educación deportiva a reflexionar en sus métodos y objetivos, en la escuela o en la universidad. ¿Cómo transmitir los contenidos de la Educación Física? ¿A qué materiales recurrir para impartir clases en aulas virtuales? ¿Cómo entrenar técnicas deportivas en escuelas de enseñanza? ¿Qué metodologías deberían ser utilizadas para evaluar el rendimiento de estudiantes y atletas?

Evidentemente, la crisis de la pandemia ha conseguido que la educación corporal se compare con la forma en que se había realizado hasta hace solo unos pocos meses. Esto parece ser lo más distante que pudiera existir desde sus conceptos básicos, que adopta al final el método de la educación a distancia. Es por ello, la importancia de instaurar planes de actividades para la Educación Física virtual en tiempo de cuarentena y como sustentar la dinámica de estas actividades cuando ya esa cuarentena se haya retirado y se vuelva a la normalidad. En todo esto es fundamental preparar a la población para el futuro venidero que debe y tiene que ser mejor y estar saludable.

Este regreso a la normalidad tiene que ser con nuevos ritmos, eventos y costumbres. Debemos desinstalar nuestra reciente y antigua vida normal, entonces, es indispensable aprender y reaprender a existir en una nueva etapa. Cuanto antes nos ocupemos y busquemos soluciones mirando al futuro, más creatividad, más innovación y más avance tendrá el deporte en todas sus versiones.

La Educación Física virtual debe poseer como propósito no solo incrementar las capacidades físicas sino vigorizar el pensamiento, la forma de proceder en el tiempo post Covid19 sea visto desde sus características, tiene que depender de la habilidad en que permanezcamos más capaces de resolver nuestros problemas con la inteligencia social. Desde la disciplina que la actividad física deportiva lleva implícita. Si asumimos el deporte como objetivo de vida fomentaremos la salud física y mental de la población.

Por esta razón, el ejercicio debe ser parte de la medicina indispensable para el Covid19, transformándose en una iniciativa atractiva para los niños, los jóvenes y, por supuesto, una alternativa necesaria para el que ya peregrina por la tercera edad. Señala la Organización Mundial de la Salud (OMS), la población más vulnerable, además las que padecen alguna enfermedad crónica (diabetes, hipertensión y obesidad, denominadas enfermedades no transmisibles, que en el mundo afectan al $71 \%$ de los habitantes). 
Por consiguiente, en las instituciones educativas más representativas en términos de ejercicio físico y salud y en las instalaciones deportivas los especialistas de la cultura física deben crear espacios y recomendaciones para motivar a las personas a continuar siendo físicamente activas durante la cuarentena. La población debe cumplir programas de diversos componentes que contiene ejercicios aerobios, fuerza, equilibrio y ejercicios de estiramiento.

Complementar con actividades cognitivas para consolidar los beneficios de la actividad física, los niños de hoy serán adultos sanos del mañana, ésta pandemia nos acompañará un buen espacio de tiempo más, es por ello, que el adulto mayor debe preservar la habilidad cognitiva y la actividad cerebral.

La pandemia por Covid19 lamentablemente ha exterminado vidas, $y$ ha puesto un reto a la inteligencia humana. Los individuos tenemos un método para compensar y desarrollar fortalezas físicas y mentales, mediante la Actividad Física. Por consiguiente, es necesario emprender proyectos para intensificar los ejercicios físicos a todos los territorios que sean posibles mediante las tecnologías de información y comunicación para preservar la vida en las mejores condiciones de salud.

Dra. Carol Elizabeth lanni-Gómez ianni.carol9@gmail.com

Instituto de Investigación y Estudios Avanzados Koinonía

Venezuela

https://orcid.org/0000-0001-7390-114X

Dra. Lesbia Ramírez-Sánchez

lesbiaramirezsanchez@hotmail.com

Universidad Nacional Experimental Francisco de Miranda

Venezuela

https://orcid.org/0000-0003-2961-9774 